\title{
Correction to: Association between heart rate variability and striatal dopamine depletion in Parkinson's disease
}

\author{
Tomomichi Kitagawa ${ }^{1} \cdot$ Tadashi Umehara $^{1}$ (1) Hisayoshi Oka ${ }^{2} \cdot$ Tomotaka Shiraishi $^{1} \cdot$ Takeo Sato $^{1} \cdot$ Hiroki Takatsu $^{1}$. \\ Atsuo Nakahara ${ }^{2}$. Hiromasa Matsuno ${ }^{1} \cdot$ Keiko Bono $^{1}$. Shusaku Omoto ${ }^{1} \cdot$ Hidetomo Murakami $^{1} \cdot$ Renpei Sengoku $^{2}$. \\ Yasuyuki Iguchi ${ }^{1}$
}

Published online: 19 October 2021

(c) Springer-Verlag GmbH Austria, part of Springer Nature 2021

\section{Correction to: Journal of Neural Transmission} https://doi.org/10.1007/s00702-021-02418-9

The original version of this article unfortunately contained a mistake. The following reference should be deleted from reference list.

The original article has been corrected.

\section{Reference}

Wei L, Chen H, Wu GR (2018) Heart rate variability associated with grey matter volumes in striatal and limbic structures of the central autonomic network. Brain Res 15(1681):14-20. https://doi.org/10. 1016/j.brainres.2017.12.024

Publisher's Note Springer Nature remains neutral with regard to jurisdictional claims in published maps and institutional affiliations.

The original article can be found online at https://doi.org/10.1007/ s00702-021-02418-9.

Tadashi Umehara tumety@jikei.ac.jp

1 Departments of Neurology, The Jikei University School of Medicine, 3-25-8 Nishi-shimbashi, Minato-ku, Tokyo 105-8461, Japan

2 Department of Neurology, Daisan Hospital, The Jikei University School of Medicine, 4-11-1 Izumihoncho, Komae-shi, Tokyo 201-8601, Japan 